\title{
Impact of a participatory program to reduce noise in a Neonatal Unit
}

\author{
Nelma Ellen Zamberlan-Amorim ${ }^{1}$ \\ Cristina Ide Fujinaga ${ }^{2}$ \\ Vanderlei José Hass ${ }^{3}$ \\ Luciana Mara Monti Fonseca ${ }^{4}$ \\ Cinira Magali Fortuna ${ }^{4}$ \\ Carmen Gracinda Silvan Scochi ${ }^{5}$
}

This study evaluated the impact of a participatory program to reduce noise in a neonatal intermediate care unit of a university hospital. A time-series quasi-experimental design was used, in which sound pressure levels were measured before and after the intervention was implemented using the Quest-400 dosimeter. Non-parametric statistical tests were used to compare noise with the level of significance fixed at $5 \%$. Results showed significant reduction of sound pressure levels in the neonatal unit after the intervention program was implemented $(p<0.0001)$. The average Leq before the intervention was $62.5 \mathrm{dBA}$ and was reduced to $58.8 \mathrm{dBA}$ after the intervention. A reduction of 7.1dBA in the average Lmax(from 104.8 to $87.7 \mathrm{dBA}$ ) and of $30.6 \mathrm{dBA}$ in the average Lpeak(from 138.1 to 107.5dBA) was observed. The program was proven to be effective in significantly reducing noise levels in the neonatal unit, although levels were still more intense than recommended.

Descriptors: Noise; Effectiveness; Neonatal Nursing; Speech, Language and Hearing Sciences.

\footnotetext{
${ }^{1}$ Audiologist, Collaborator Professor, Universidade Estadual do Centro-Oeste do Paraná, Irati, PR, Brazil. Doctoral Student, Escola de Enfermagem de Ribeirão Preto, Universidade de São Paulo, WHO Collaborating Centre for Nursing Research Development, SP, Brazil. E-mail: nelmaellen@gmail.com.

${ }^{2}$ Audiologist, Adjunct Professor B, Universidade Estadual do Centro-Oeste do Paraná, Irati, PR, Brazil. Post-doctoral fellow, Escola de Enfermagem de Ribeirão Preto, Universidade de São Paulo, WHO Collaborating Centre for Nursing Research Development, SP, Brazil. Researcher Funding Scholarship, Conselho de Desenvolvimento científico e Tecnológico (CNPq), Brazil. E-mail: cifujinaga@gmail.com.

${ }^{3}$ Physicist, Ph.D. in Sciences. E-mail: vjhaas@uol.com.br.

${ }^{4}$ RN, Ph.D. in Nursing, Professor, Escola de Enfermagem de Ribeirão Preto, Universidade de São Paulo, WHO Collaborating Centre for Nursing Research Development, SP, Brazil. E-mail: Luciana - lumonti@eerp.usp.br, Cinira - fortuna@eerp.usp.br.

${ }^{5}$ RN, Ph.D. in Nursing, Full Professor, Escola de Enfermagem de Ribeirão Preto, Universidade de São Paulo, WHO Collaborating Centre for Nursing Research Development, SP, Brazil. E-mail: cscochi@eerp.usp.br .
}

Corresponding Author:

Carmen Gracinda Silvan Scochi

Universidade de São Paulo. Escola de Enfermagem de Ribeirão Preto

Departamento de Enfermagem Materno-Infantil e Saúde Pública

Av. dos Bandeirantes, 3900

Bairro: Monte Alegre

CEP: 14040-902 Ribeirão Preto, SP, Brasil

E-mail: cscochi@eerp.usp.br 


\section{Impacto de um programa participativo de redução do ruído em unidade neonatal}

O objetivo deste estudo foi avaliar o impacto de um programa participativo na redução do ruído ambiente em uma unidade neonatal, de um hospital universitário. Utilizou-se delineamento quase-experimental do tipo tempo-série, no qual os níveis de pressão sonora foram dimensionados antes e após a implantação do programa de intervenção, utilizando o dosímetro Quest-400. Para a análise comparativa do ruído, utilizaram-se os testes estatísticos não-paramétricos $(\alpha=0,05)$. Constatou-se redução significativa dos níveis de pressão sonora da unidade neonatal, após a implantação do programa de intervenção $(p<0,0001)$. O Leq médio foi de 62,5dBA antes da intervenção e reduziu para 58,8dBA após a intervenção. Houve redução de 7,1dBA no Lmax médio (de 104,8 para $87,7 \mathrm{dBA}$ ) e de $30,6 \mathrm{dBA}$ no Lpeak médio (de 138,1 para $107,5 \mathrm{dBA}$ ). Concluiu-se que o programa foi efetivo na redução do nível sonoro da unidade neonatal, embora ainda se mantenha mais intenso que o recomendável.

Descritores: Ruído; Efetividade; Enfermagem Neonatal; Fonoaudiologia.

\section{Impacto de un programa participativo de reducción de ruido en una unidad neonatal}

El objetivo fue evaluar el impacto de un programa participativo en la reducción del ruido ambiente en una unidad neonatal de un hospital universitario. Se utilizó delineamiento casi-experimental del tipo tiempo-serie, en el cual los niveles de presión sonora fueron mensurados antes y después de la implantación del programa de intervención, utilizando el dosímetro Quest-400. Para el análisis comparativo del ruido, se utilizaron las pruebas estadísticas no paramétricas $(\alpha=0,05)$. Se constató reducción significativa de los niveles de presión sonora de la unidad neonatal después de la implantación del programa de intervención ( $p<0,0001$ ). El Leq medio fue de 62,5dBA antes de la intervención y se redujo para 58,8dBA después de la intervención. Hubo reducción de 7,1dBA en el Lmax medio (de 104,8 para $87,7 \mathrm{dBA}$ ) y de $30,6 \mathrm{dBA}$ en el Lpeak medio (de 138,1 para $107,5 \mathrm{dBA}$ ). Se concluye que el programa fue efectivo en la reducción del nivel sonoro de la unidad neonatal, a pesar de que todavía se mantiene más intenso que lo recomendable.

Descriptores: Ruido; Efectividad; Enfermería Neonatal; Fonoaudiología.

\section{Introduction}

The neonatal environment is usually characterized as being an over-stimulating environment that may compromise the recovery of newborns, the team's work capacity and the satisfaction of companions. Neonatal units present intense sound levels, which justifies the implementation of interventions aiming to reduce environmental noise ${ }^{(1)}$.

There is a concern with the physical environment of health services, including hospitals and intensive care units, based on health policies directed to the humanization of care and focused on the philosophy of providing developmental care to patients, especially in neonatal units, the place of interest in this study.
From the perspective of humanization, 'ambience' in health refers to the treatment given to the physical space seen as a social and professional area where interpersonal relationships are held. The space should be welcoming and provide personal warmth, solutions and humanized care(2). The construction of healthy spaces includes the control and reduction of environmental noise.

The American Academia of Pediatrics( ${ }^{(3)}$ recommends that neonatal units develop routine measures and monitor noise such that it does not exceed $45 \mathrm{~dB}$ (decibels). The Brazilian Technical Standards Association $(A B N T)^{(4)}$ does not specify levels for these units, while 
the NBR-10152 recommendations for noise levels compatible with humans' acoustic comfort in hospitals (rooms, nursing wards, and nurseries) are 35dBA SPL (ideal) and 45dBA SPL (acceptable). The Committee to Establish Recommended Standards for Newborn ICU Design, coordinated by White ${ }^{(5)}$ in the Seventh Consensus Committee ("Standard 23: Acoustic Environment"), established continuous (basal) and operational noise levels for nurseries where infants remain hospitalized and rest areas for adults (family members and caregivers team): $L_{\text {eq }}$ of $45 d B A, L_{10}$ of $50 d B A$ and $L_{\max } 65 d B A$. The recommended noise levels are more intense $(+5 \mathrm{~dB})$ in the combination of background and operational noise in relation to the previously established parameters $\left(\mathrm{L}_{\mathrm{eq}}{ }^{*}\right.$ of $50 \mathrm{dBA}, \mathrm{L}_{10}{ }^{\dagger}$ of $55 \mathrm{dBA}$ and $\mathrm{L}_{\max }{ }^{\ddagger} 70 \mathrm{dBA}$ ) for the team's work areas and communal areas for the families and rest areas for the teams. This standard is recommended both for Intensive Care Units (ICU) and Intermediate Neonatal Care Units (NICU) ${ }^{(5)}$.

There are no intervention studies in Brazil that evaluate the effectiveness of systematized actions to reduce noise pollution in neonatal units caring for patients at risk, that is, individuals vulnerable to damage and injuries. It is believed that the solution for such a problem is only possible when considering the issue of noise as a chain whose interconnected links represent a set of inter-sector actions directed to the physical structures, technological and human resources, involving managers, health professionals and the administrative and support areas dedicated to newborns and their families. Breaking any of these links compromises the control and reduction of environmental noise in neonatal units.

Therefore, this study evaluates the impact of a participatory program intended to reduce environmental noise in a neonatal unit of a university hospital. We expect the study to provide evidence to support the organization of nursing practice and the health work process in healthcare facilities in relation to the construction of healthy environments for both patients and caregivers.

\section{Method}

This study used a time-series quasi-experimental design in which the Sound Pressure Levels (SPL) were measured at two points in time, before and after the intervention program was implemented, using the dosimeter Quest-400. This device was positioned in the central area of the nursing ward in the neonatal unit of a university hospital with minimal manipulation and suspended $70 \mathrm{~cm}$ from the ceiling(6). Noise was measured at each stage for two consecutive weeks, 12 hours a day: from 7pm to 7am in the first week and from 7am to $7 \mathrm{pm}$ in the second. The project was approved by the Research Ethics Committee at the university hospital.

The program to reduce noise in the NICU was developed jointly with the neonatal team: at least one representative of each profession (physician, nurse, nursing technician and nursing auxiliary, speech therapist, and social worker) attended discussion tables, in addition to mothers accompanying the children and the researchers. It is worth highlighting the expressive participation of the nursing team in the group meetings. During the nine discussion sessions held weekly and mediated by the researcher based on the problematization methodology $(7)$, the effects and sources of noises were discussed and then the group members proposed actions and executed them in order to reduce noise. The actions were grouped into two goals: sensitize the team and family members concerning the noise problem in the NICU and improve the management of equipment and environment to reduce noise. The developed actions were: diminishing vocal intensity; placing notes on garbage bins and incubators for careful management; fixing anti-impact guards in cabinet doors and drawers; reducing the intensity of phone rings; discussing the noise problem in a group setting; and attempting to change shifts with the entire nursing team together; collecting the opinions and suggestions of the team to reduce noise through a questionnaire; promoting a contest to hang posters in the NICU; affixing two noise thermometers in the NICU for the team to handle them based on auditory sensation, among others.

Data were stored in a database using QuestSuit ${ }^{M R}$ for Windows, which provides numerical and graphic analysis. In the descriptive analysis we highlight the use of inter-quartile range (I.R.) as a measure of variability, a separatrix that allows one to indicate the size of difference between the $3^{\text {rd }}$ and the $1^{\text {st }}$ quartile.

The non-parametric Wilcoxon, Kruskal-Wallis and Mann-Whitney tests were used $(\alpha=0.05)$ in the

* $\mathrm{L}_{\mathrm{eq}}$ : average level of energy equivalent to the $\mathrm{SPL}$, in this case measured in $\mathrm{dBA}^{(5)}$.

$+L_{10}$ : represents the SPL above which it exceeded $10 \%$ of the total recorded ${ }^{(5)}$.

$\neq L_{\text {max }}$ : peaks of acoustic energy, which are the highest SPL during the specific record period(5). 
Statistical Package for the Social Sciences (SPSS) for the comparative analysis of noise before and after the intervention.

In order to evaluate the impact of the reduction of noise in the days of the week, a new variable was developed, considering days subdivided into weekdays and weekends. The new variable stored the difference between the noise before and after the intervention for each measure $\left(L_{e q}, L_{\text {max }}\right.$ and $\left.L_{\text {peak }}\right)$. Hence, the descriptive and inferential analyses refer to this difference, measuring the impact of intervention in reducing noise, called summary comparative measure: $\mathrm{L}_{\text {eq (before - after)' }} \mathrm{L}_{\text {max }}$ (before - after) and $\mathrm{L}_{\text {peak (before - after) }}$.

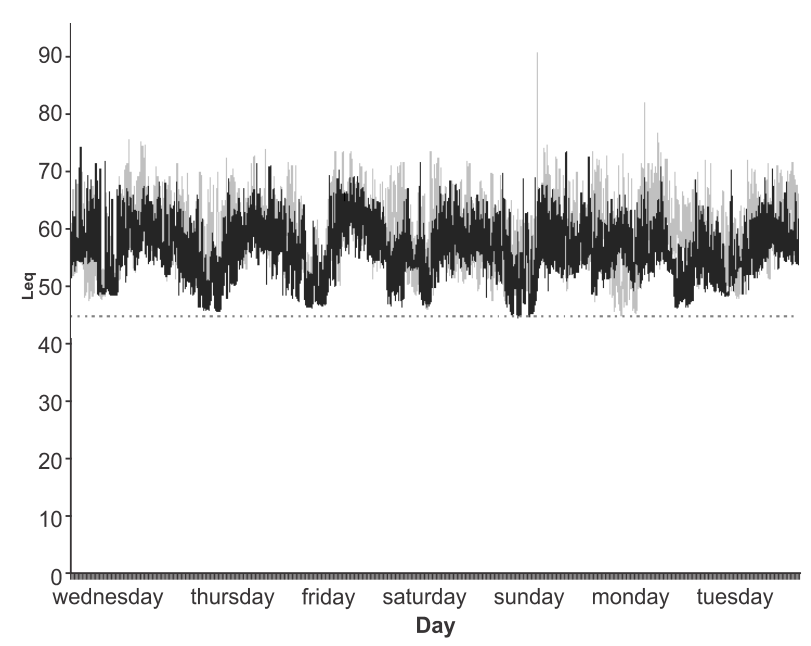

\section{Results}

A total of 10,080 minutes by stage of measurement were obtained for each measure $\left(L_{e q}, L_{\text {max }}\right.$ and $\left.L_{\text {peak }}\right)$, totaling 20,160 minutes recorded in the total collection in the SPL corresponding to 336 hours in two stages.

The dotted line corresponds to what is recommended(8). The curves present the gross values, minute to minute, of $\mathrm{L}_{e q} \mathrm{~L}_{\max \text { and }} \mathrm{L}_{\text {peak }}$ identified by dark lines in the pre-intervention period and light lines in the post intervention period of the seven days distributed in 24 hours of this indicator in the NICU of the university hospital in Ribeirão Preto, SP, Brazil, 2008-2009.

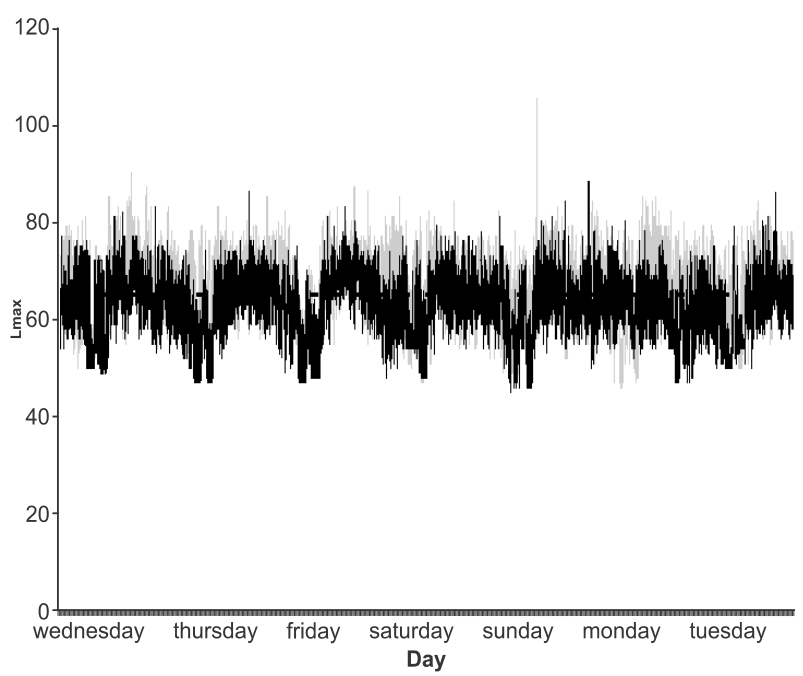

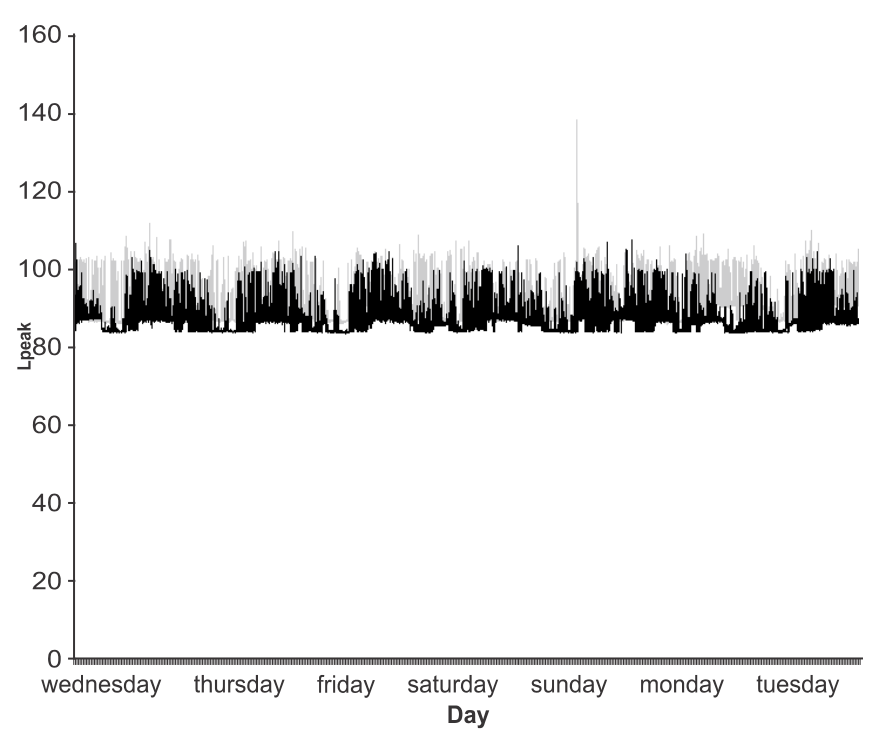

The dotted line corresponds to what is recommended(8). The curves present the gross values, minute to minute, of $L_{e q} L_{\text {max }}$ and $L_{p e a k}$ identified by dark lines in the pre-intervention period and light lines in the post intervention period of the seven days distributed in 24 hours of this indicator in the NICU of the university hospital in Ribeirão Preto, SP, Brazil, 2008-2009.

Figure 1 - Time evolution of values of $\mathrm{L}_{\mathrm{eq}} \mathrm{L}_{\max }$ and $\mathrm{L}_{\text {peak }}$ obtained in the pre- and post- intervention periods, represented by dotted and continuous lines, respectively 
Figure 1 shows that all the measured minutes of $\mathrm{L}_{\text {eq }}$ before the intervention were above $40 \mathrm{dBA}$ as well as after intervention; $99.95 \%$ of the measures were above this reference threshold.

The same figure shows that the 6,291 (62.41\%) records of $L_{\max }$ were greater than what is recommended, both before and after the intervention, which were reduced to $4,262(42.3 \%)$ records. The time evolution of the $\mathrm{L}_{\text {peak }}$ exceeded $80 \mathrm{dBA}$ in all the obtained records, especially before the intervention.

Table 1 - Descriptive measures in $\mathrm{dB}$ and the results of the Wilcoxon text comparing the pre- and postintervention values of $\mathrm{L}_{\mathrm{eq}}, \mathrm{L}_{\text {max }}$ and $\mathrm{L}_{\text {peak }}$ obtained in the 10,080 records during the measurement of noise in the NICU at the university hospital in Ribeirão Preto-SP, Brazil, 2008/2009

\begin{tabular}{|c|c|c|c|c|c|c|}
\hline \multirow{2}{*}{$\begin{array}{c}\text { Descriptive } \\
\text { measure }\end{array}$} & \multicolumn{2}{|c|}{$\mathrm{L}_{\mathrm{eq}}$} & \multicolumn{2}{|c|}{$\mathrm{L}_{\max }$} & \multicolumn{2}{|c|}{$L_{\text {peak }}$} \\
\hline & Pre & Post & Pre & Post & Pre & Post \\
\hline Average & 62.5 & 58.8 & 104.8 & 87.7 & 138.1 & 107.5 \\
\hline Minimum & 45.1 & 44.7 & 46.0 & 45.0 & 86.0 & 84.0 \\
\hline Maximum & 90.8 & 74.3 & 105.0 & 88.0 & 138.1 & 108.0 \\
\hline Median & 58.9 & 56.4 & 67.0 & 63.0 & 88.5 & 86.6 \\
\hline Inter-quartile Range & 7.3 & 6.4 & 9.0 & 8.0 & 4.5 & 4.0 \\
\hline$P$ value & \multicolumn{2}{|c|}{$<0.001^{*}$} & \multicolumn{2}{|c|}{$<0.001^{*}$} & \multicolumn{2}{|c|}{$<0.001^{*}$} \\
\hline
\end{tabular}

*Wilcoxon test: results statistically significant for $\alpha=0.05$

There was a significant reduction in the SPL of NICU with the implementation of the intervention program $(p<0.0001)$. The $L_{e q}$ general average of environmental noise was 62.5dBA before the intervention and was reduced to $58.8 \mathrm{dBA}$ after the intervention, hence there was a $3.7 \mathrm{dBA}$ reduction of SPL.

Table 2 - Comparison of the 10,080 values of $L_{\text {eq }} L_{\max }$ and $L_{\text {peak }}$ pre- and post-intervention in relation to the median, maximum, minimum values and inter-quartile range obtained during the weekends and weekdays in the NICU of the university hospital in Ribeirão Preto-SP, Brazil, 2008/2009

\begin{tabular}{|c|c|c|c|c|c|c|}
\hline \multirow{2}{*}{ Descriptive measure } & \multicolumn{2}{|c|}{$\mathbf{L}_{\text {eq }}$} & \multicolumn{2}{|c|}{$\mathbf{L}_{\max }$} & \multicolumn{2}{|c|}{$L_{\text {peak }}$} \\
\hline & Pre & Post & Pre & Post & Pre & Post \\
\hline \multicolumn{7}{|l|}{ Weekdays } \\
\hline Minimum & 45.1 & 45.8 & 46.0 & 47.0 & 86.0 & 84.0 \\
\hline Maximum & 82.0 & 74.3 & 90.0 & 86.0 & 111.6 & 107.0 \\
\hline Median & 59.2 & 56.5 & 67.0 & 63.0 & 89.1 & 86.6 \\
\hline Inter-quartile range & 7.4 & 6.7 & 9.0 & 9.0 & 4.9 & 4.0 \\
\hline \multicolumn{7}{|l|}{ Weekends } \\
\hline Minimum & 46.2 & 44.7 & 47.0 & 45.0 & 86.0 & 84.0 \\
\hline Maximum & 90.8 & 73.5 & 105.0 & 88.0 & 138.1 & 108.0 \\
\hline Median & 58.2 & 56.3 & 66.0 & 63.0 & 87.6 & 86.2 \\
\hline Inter-quartile range & 6.9 & 5.7 & 9.0 & 8.0 & 4.0 & 4.0 \\
\hline
\end{tabular}

All these differences between the summary measures for the days of the week (weekdays and weekends) were statistically significant for $L_{\text {eq (before - after) }}$ $(p<0.001)$ and $L_{\text {peak (before - after) }}(p<0.001)$, though the same was not the case for $L_{\max \text { (before - after) }}(p=0.312)$.

The effect of the intervention in relation to the day shifts (morning, afternoon and night) was compared in the pre- and post-program implementation of noise reduction. Considering that there was a statistically significant difference for $\mathrm{L}_{\text {eq (before - after) }}$ and $\mathrm{L}_{\text {peak (before - after) }}{ }^{\prime}$ multiple comparisons were performed between pairs of shifts, employing the Mann-Whitney test. A statistically significant difference was found for $L_{\text {eq (before - after) }}$ between the morning and afternoon shifts $(p=0.019)$, morning and afternoon $(p=0.001)$, and afternoon and night shifts $(p=0.002)$. There was a statistically significant difference for $L_{\text {peak (before - after) }}$ between the morning and afternoon shifts $(p=0.004)$, and between the morning and night shifts $(p<0.001)$, though there was no statistically significant difference between the afternoon and night shifts $(p=0.055)$

\section{Discussion}

The sound level of 45dBA recommended by international standards ${ }^{(3,5)}$ for NICUs and ICUs was exceeded, except in a total of five minutes of the postintervention period that reached $\mathrm{L}_{\mathrm{eq}}$ of $44.7 \mathrm{dBA}$.

All published studies also found SPL above the limit of $45 \mathrm{dBA}$, with the exception of one study(9) that obtained $44 \mathrm{~dB}$ in a neonatal unit in Greece, though with non-systematic environmental measurements and without an intervention program.

It is worth noting that international standards were developed for neonatal environments that would be acoustically designed(5), which does not correspond to the reality of Brazilian neonatal units. Additionally, no consensus in relation to a safe sound level to which newborns should be allowed to be exposed during their stay in neonatal environment has been reached ${ }^{(5)}$.

All the average sound levels obtained in this study were above that recommended by the WHO $\left(L_{e d}\right.$ maximum of $40 \mathrm{~dB}$ for the internal area during the day, reduced from 5 to $10 \mathrm{~dB}$ in the night shift(10) ) and by the Brazilian standard already mentioned ${ }^{(4)}$. Such values were close to those obtained in the same studied setting four years ago with an average level of noise of $60.8 \mathrm{dBA}$ and median of $59.4 \mathrm{dBA}^{(8)}$.

Despite methodological differences among the few intervention studies that evaluate the impact of actions on the noise levels of neonatal units, similarity is observed 
in their results with a reduction of $3.66 \mathrm{~dB}^{(11)}$ and $4 \mathrm{~dB}^{(11-}$

12). Other studies obtained even greater reductions: $5 \mathrm{~dB}$ and $8 \mathrm{~dB}$ in American studies(13-14) and $11 \mathrm{~dB}$ in an Indian study $^{(15)}$. Only the Chinese ${ }^{(16)}$ found a lesser reduction $(2 \mathrm{~dB})$, although also statistically significant.

On the contrary, when comparing SPL at three different points in time after changes introduced in an NICU in North Carolina, researchers verified a gradual increase in the $\mathrm{L}_{\text {eq }}$, passing from 54.1 to 54.7 and then $55.6 \mathrm{~dB}^{(17)}$. Much smaller values were obtained by Chinese authors: $L_{\max }$ of $57 \mathrm{dBA}$ in ICU with divisions and 78dBA in areas without divisions ${ }^{(18)}$. Others also obtained less intense $L_{\max }$ values than those found in this study, even with its gradual increase verified in the three time measures, from 60.3 to 61.9 and $62.4 \mathrm{~dB}^{(19)}$.

Researchers obtained less intense levels and a smaller reduction (5.81dBA) in $L_{\max }$ when comparing SPL in a control nursing ward (62.77dBA) with another nursing ward whose physical structure was rebuilt and where developmental care was implemented (56.96dBA), in an ICU at the Arnold Palmer Hospital for Children and Women in Orlando, Florida, USA(13).

In a quasi-experimental study conducted in the Children's Regional Hospital at Cooper University Hospital, Texas, USA, the $L_{\max }$ remained between 78 and $100 d B A$ after the team's behavioral changes but were reduced to 68 and $84 \mathrm{dBA}$ after the physical area was renovated ${ }^{(20)}$.

Hence, values below $L_{\text {peak }}$ were found in an ICU in Texas ${ }^{(21)}$, in a comparative study conducted in the nursing wards of two ICUs ( $A$ - the oldest and $B$ - the most recent building) of large hospitals in Harris County in Houston, Texas, USA. The authors divided the values of $L_{\text {peak }}$ into three intervals: below $80 \mathrm{~dB}$, between 80 and $90 \mathrm{~dB}$, and above $90 \mathrm{~dB}$. There was no statistically significant difference between the neonatal units or among the nursing wards for the two shorter intervals (below $80 \mathrm{~dB}$ and from 80 to $90 \mathrm{~dB}$ ) though the values below $80 \mathrm{~dB}$ were more frequent in ICU $B$, nursery levels II and III, compared to ICU A, nurseries II and III. On the other hand, there was a statistically significant difference for the $L_{\text {peak }}$ values above 90dB $(p=0.0001)$, which exceeded this limit in $6.3 \%$ of the measures in ICU $A$ and in $2.8 \%$ in ICU $B$, and were more frequently recorded in the three nursing wards of ICU $A(p<0.0001)$.

As expected, the minimum values of $L_{e q}, L_{\max }$ and $L_{\text {peak }}$ were reduced, though with only slight variability before and after the intervention, because these data refer to a single measure per event. In contrast, the maximum values were intensely reduced after the intervention program: 16.5dBA, 17.0dBA and 30.1dBA respectively for such measures. Hence, a greater impact of the intervention is observed in $\mathrm{L}_{\text {peak. }}$.

To better contextualize the results of the impact produced in the sound levels in neonatal environments it is important to describe and discuss the interventions included in these studies.

In this study the methodology included the active participation of the multi-disciplinary team in the development of the intervention program, which included a set of actions, many of them already recommended by other authors, such as: presenting a video to sensitize the team concerning the effects of noise on newborns ${ }^{(11,14-15)}$, and also in regard to the need to change behavior to reduce noise ${ }^{(12,14)}$, including the team in the discussion of the problem and actions to be implemented ${ }^{(14)}$, making and hanging posters with phrases warning for the need to keep silence ${ }^{(11-12,15)}$, installing anti-impact guards on drawers and cabinet doors ${ }^{(21)}$, paying attention to equipment alarms ${ }^{(5,16,22)}$, and implementing daily moments of silence in the neonatal unit ${ }^{(12,22)}$. As opposed to the previously mentioned studies, this study's group proposed and implemented creative actions to allow a greater participation of the remaining members of the team such as a context of phrases and management of noise thermometers installed in the NICU nursing wards.

The effects of the actions proposed in this study caused greater anxiety in the nursing team when they realized the responsibility to visually check the unit's alarms. They also called the reduction in noise stemming from the 'cascading effect': when noise in the environment is loud the team members tend to speak louder. Researchers point to the need for investment in structural renovation and technological control to reduce noise. They have concluded that the implemented protocol presented more cost-effectiveness in nursing wards with greater levels of noise, such as respiratory care and recovery rooms ${ }^{(14)}$.

Contrary to these results, American researchers have shown that the use of a new communication system in the neonatal environment, the installation of an automatic paper towel dispenser and the replacement of incubators in an ICU in North Carolina contributed to a significant increase $(p<0.001)$ of $S P L$ with $L_{e q}$ of 54.1 to $55.6 \mathrm{~dB}$ and $L_{10}$ of 56.5 to $57.9 \mathrm{~dB}$. Therefore, the authors conclude that investment in high-cost technological resources do not ensure effective reduction in environmental noise ${ }^{(19)}$.

We agree with such a statement given the method chosen in this study and the significant impact obtained. However, the comparison of these last two 
studies revealed that the reduction obtained is a result of interventions affecting the environments' physical structure, such as floor, ceiling, and sound absorption panels, which is in agreement with the recommendations found in international standards ${ }^{(5)}$. Hence, this and other published studies provide evidence concerning the positive impact of actions related to the infrastructure, equipment and behavior of caregivers in reducing noise in neonatal units in many countries.

It is believed that nursing professionals play a decisive role in preventing and controlling environmental noise because they remain, for the most part, within neonatal units and are involved in the direct care provided to newborns and families and can therefore integrate the neonatal team, family members and employees in actions seeking to reduce noise.

There are few studies analyzing noise on the second day of the week and those that perform such analysis are descriptive and present methodological differences, which are presented as follow.

A previous study carried out in this same ICU found some differences among weekdays and weekends. The variability during weekdays of $\mathrm{L}_{\text {eq }} \mathrm{L}_{\text {peak }}, \mathrm{L}_{\text {max }}$ and $\mathrm{L}_{\text {min }}$ was 20.8dBA, 23.6dBA, 42.8dBA and 1.4dBA, respectively. The $L_{\text {eq }}$ per weekday was greater (62.3dBA) on Tuesdays and lesser (59.5dBA) on Saturdays. The $L_{\max }$ by day of the week was greater on Monday and occurred at 8:48am (90.9dBA) while the lesser was on Wednesday at $12: 26 \mathrm{pm}(52.1 \mathrm{aBA})^{(6)}$. Even though the SPL are intense, the results suggest that the noisiest days are on the weekends.

Another study carried out in the ICU of this same hospital also found intense SPL every day, including weekends. The $L_{\text {eq }}$ varied from 61.5 to $64.7 \mathrm{dBA}$, occurred on Sundays, the average was 64dBA in the first week, $62.5 \mathrm{dBA}$ in the second and $63.2 \mathrm{dBA}$ on the third. The daily $L_{\text {max }}$ varied from 81.4 to $94.2 d B A$, SPL values on Thursday; the greatest values per week were 92.5dBA in the first week, 89.9dBA in the second and 94.2dBA in the third. The lowest $L_{\text {peak }}$ was $105.7 \mathrm{~dB}$ and the greatest was $114.1 \mathrm{~dB}$, the greatest total values were $114.1 \mathrm{~dB}$; $112.6 \mathrm{~dB}$ and $112.7 \mathrm{~dB}$, in the first, second and third weeks respectively(23)

The analysis of comparative summary measures of $\mathrm{L}_{\text {eq (before - after) }}, \mathrm{L}_{\text {max (before - after), }} \mathrm{L}_{\text {peak (before - after) }}$ in weekdays and weekends revealed that weekends are less noisy than weekdays, which corroborate the obtained results ${ }^{(6)}$.

In agreement with these results, only the quasiexperimental study presented $\mathrm{L}_{\mathrm{eq}}, \mathrm{L}_{10}$ and $\mathrm{L}_{\text {max }}$ by shifts, whose SPL were significantly $(p<0.001)$ more intense during the day compared to the night shift $\left(\mathrm{L}_{\mathrm{eq}}-\mathrm{F}\right.$ $[1: 86,459]=0.23 ; p<0.001 ; L 10-F[1: 86,459]=$ $\left.0.23 ; p<0.001 ; L_{\max }-F[1: 86,459]=0.23 ; p<0.001\right)$.

Another study without intervention conducted in the same ICU four years ago reported intense SPL during all the shifts (day and night) ${ }^{(6)}$.

Peak values between 90.8 and $123.4 \mathrm{bBC}$ were found, which were more intense during the night shift (123.4dBC), followed by the morning (103.4dBC) and afternoon $(90.8 \mathrm{dBC})$ shifts $^{(24)}$. The morning shift was the noisiest in another neonatal service in which, for example, conversations were held among people and jets of water from the sink to wash hands were observed, which reached the maximum level of noise of $80.4 \mathrm{~dB}$, above the national recommendation ${ }^{(25)}$.

Given the studies presented, we highlight the importance given to the participatory program developed in this study to propose the reduction of intense noise levels in neonatal units given the low cost of actions, despite limitations and difficulties faced such as reduced time to gather the team to devise actions and implement them aiming to reduce noise in the work routine.

\section{Conclusion}

The conclusion is that the participatory program positively impacted the neonatal unit, advancing the joint construction of a proposal to reduce noise, breaking with the dichotomy of the specialist who knows and teaches versus workers, thus significantly reducing the environmental sound intensity.

However, despite such a reduction, sound levels in the NICU were still more intense than what is recommended, which indicates the need for other actions, in addition to a lack of evidence of such effects in the long term, marking both a limitation of this study and also a motivation for future research.

\section{Referências}

1. Rodarte MDO, Scochi CGS, Leite AM, Fujinaga CI, Zamberlan NE, Castral TCO. Ruído gerado durante a manipulação das incubadoras: implicações para o cuidado de enfermagem. Rev. Latino-Am. Enfermagem. 2005;13(1):297-306.

2. Ministério da Saúde (BR). 2006. Ambiência. Brasília (DF): Ministério da Saúde; 2006.

3. American Academy of Pediatrics. Committee on environmental health. Noise: a hazard for the fetus an newborn. Pediatrics. 1997;100(4):724-7. 
4. Associação Brasileira de Normas Técnicas (BR). NBR 02:135. 01-004. Acústica: avaliação do ruído ambiente em recinto de edificações visando o conforto dos usuários-procedimento. Rio de Janeiro (RJ): Associação Brasileira de Normas Técnicas; 1999.

5. White RD. Recommended standards for the newborn ICU. J Perinatol. 2007; 23:S5-21.

6. Zamberlan NE, Ichisato SMT, Rodarte MDO, Fujinaga CI, Hass VJ, Scochi CGS. Ruído na Unidade de Cuidado Intermediário Neonatal de um hospital universitário. Ciênc Cuidado Saúde. 2008;7(4):431-8.

7. Ceccim RB. Educação permanente em saúde: descentralização e disseminação de capacidade pedagógica na saúde. Ciênc Saúde Colet. 2005;10(4):975-86.

8. Committee to Establish Recommended Standards for Newborn ICU Design (FL). Recommended standards for newborn ICU design noise abatement-standards 23 . Report of the sixth consensus conference on newborn ICU design. Clearwater Beach (FL); 2007.

9. Anagnostakis D, Petmezakis J, Messaritakis J, Matsaniotis N. Noise pollution in Neonatal Units: a potential hazard. Acta Paediatr Scand. 1980;69(6):771-3.

10. World Health Organization. Guidelines values. Guidelines for community noise page. Londres (Westminster); 1999.

11. Johnson AN. Adapting the Neonatal Intensive Care environment to decrease noise. J Perinatol Neonat Nurs. 2003;17(4):280-8.

12. Gayle T, Whittmann-Price RA. Project noise buster in the NICU. How one facility lowered noise levels when caring for preterm infants. Am J Nurs. 2006;106(5):64AA-5DD.

13. Byers JF, Waugh WR, Lowman LB. Sound level exposure of high-risk infants in different environmental conditions. Neonat Network. 2006;25(1):25-32.

14. Elander G, Hellström G. Reduction of noise levels in Intensive Care Units for Infants: evaluation of an intervention program. Heart \& Lung 1995;21(5):376-9. 15. Ramesh A, Rao S, Sandeep G, Nagapoornima M, Srilakshmi V, Dominic M. et al. Efficacy of a low cost protocol in reducing noise levels in the Neonatal Intensive Care Unit. Indian J Pediatr. 2009;76(5):475-8. 16. Chang YJ, Ya-Jung Pan BSN, Lin YJ, Yan-Zen Chang $\mathrm{BE}$, Lin $\mathrm{CH}$. A noise-sensor light alarm reduces noise in the Newborn Intensive Care Unit. Am J Perinatol. 2006;23(5):265-71.

17. Brandon DH, Ryan DJ, Barnes AH. Effect of environmental changes on noise in the NICU. Neonat Network 2007;26(4):S5-S10.
18. Chen $\mathrm{HL}$, Chen $\mathrm{CH}$, Wu CC, Huang HJ, Wang TM, Hsu

$\mathrm{CC}$. The influence of Neonatal Intensive Care Unit design on sound level. Pediatr Neonatol. 2009;50(6):270-4.

19. Williams $A L$, Van Drongelen W, Lasky RE. Noise in contemporary Neonatal Intensive Care. J Acoustical Soc Am. 2007;121(5):2681-90.

20. Philbin MK, Gray L. Changing levels of quiet in an Intensive Care Nursery. J Perinatol. 2002;20(6):455-60. 21. Livera MD, Priya B, Ramesh A, Suman-Rao PN, Nagapoornima M, Ramakrishnan $A C$, et al. Spectral analysis of noise in the Neonatal Intensive Care Unit. Indian J Pediatric 2008;75(3):217-22.

22. Wachman EM, Lahav A. Tha effects of noise on preterm infants in the NICU. Arch Dis Child Fetal Neonatal. 2010;95(1):Fa14.

23. Ichisato SMT. Ruído em Unidade de Cuidado Intensivo Neonatal de um hospital universitário de Ribeirão Preto - SP [tese de doutorado]. Ribeirão Preto (SP): Escola de Enfermagem de Ribeirão Preto da Universidade de São Paulo; 2004. 170 p.

24. Kakehashi TY, Pinheiro EM, Pizzarro G, Guilherme A. Nível de ruído em uma Unidade de Terapia Intensiva Neonatal. Acta Paul Enferm. 2007;20(4):404-9.

25. Cardoso MVLML, Chaves EMC, Bezerra MGA. Noise and sounds in the neonatal unit. Rev Bras Enferm. $2010 ; 63(4): 561-6$.
Received: Jan. $18^{\text {th }} 2011$ Accepted: Ago. 15 th 2011 